\section{'AMAPOLO' Y 'MULATO', NUEVAS VARIEDADES DE FRIJOL PARA EL ESTADO DE JALISCO, MÉXICO}

\section{'AMAPOLO’ AND ‘MULATO', NEW DRY BEAN VARIETIES FOR JALISCO STATE, MÉXICO}

\author{
Rogelio Lépiz Ildefonso ${ }^{1 \star}$, Santiago Sánchez \\ Preciado ${ }^{1}$, Alfredo González Ávila ${ }^{2}$, Eduardo López \\ Alcocer ${ }^{1}$ y Eduardo Rodríguez Guzmán ${ }^{1}$
}

\footnotetext{
${ }^{1}$ Universidad de Guadalajara. km 15.5 Carr. Guadalajara-Nogales, Las Agujas, Zapopan, Jal. ${ }^{2}$ Instituto Nacional de Investigaciones Forestales, Agrícolas y Pecuarias. Parque Los Colomos, Guadalajara, Jal.

* Autor para correspondencia (rlepiz@cucba.udg.mx)
}

En el Estado de Jalisco, México, la producción de frijol (Phaseolus vulgaris L.) en 1980 fue de $48381 \mathrm{t}$, cantidad que en 2008 se redujo a 14419 t; tal reducción fue equivalente a 70 \% (SIAP, 2010). Este fenómeno transformó a Jalisco de un estado productor a uno "importador" de frijol, ya que la demanda estatal estimada en 2008 para cubrir las necesidades de la población fue de 67520 t de esta leguminosa.

Con base en lo anterior, el Proyecto de Frijol de la Universidad de Guadalajara (UDG) con participación del Instituto Nacional de Investigaciones Forestales Agrícolas y Pecuarias (INIFAP), inició actividades de mejoramiento genético del frijol en el año 2000, acciones que se fortalecieron en 2003 con recursos de la Fundación Produce Jalisco, del Consejo Estatal de Ciencia y Tecnología de Jalisco y de la empresa Productos Verde Valle. El objetivo de dicho proyecto es desarrollar variedades de frijol de grano preferente y alto rendimiento, para las regiones Centro y Sur de Jalisco, áreas donde las condiciones ambientales de producción son favorables.

La obtención de nuevas variedades de frijol inició con la introducción de germoplasma nacional e internacional, con dos propósitos principales: a) la identificación de progenitores donantes de genes de adaptación y resistencia a enfermedades, para ser cruzados con variedades de frijol tipo 'Peruano' de Sinaloa, y b) la búsqueda de líneas de alto valor agronómico y grano comercial, que pudieran sumarse de manera temprana a la producción de frijol en el Estado de Jalisco (Lépiz et al., 2001).
Los viveros nacionales e internacionales de fuentes de resistencia a enfermedades, compuestos de variedades y líneas avanzadas, se evaluaron en 2000 y 2002 bajo condiciones de campo en serie sencilla, con inclusión de variedades testigo por cada 10 materiales introducidos. En esta fase, además de seleccionar progenitores para el programa de cruzamientos, se logró identificar genotipos de excelente adaptación al centro de Jalisco, con resistencia a enfermedades como bacteriosis de halo [Pseudomonas syringae pv. phaseolicola (Burkh.)] y antracnosis [(Colletotrichum lindemuthianum (Sacc. et Magn.) Scrib.], con buen potencial de rendimiento y grano comercial. Estos materiales promisorios fueron luego evaluados por dos años en ensayos de rendimiento en el campo experimental de Zapopan de la UDG (2002 y 2003). Posteriormente las mejores líneas se evaluaron en un ensayo de rendimiento regional (2003 y 2004) y en parcelas de validación técnica en sitios de las regiones Centro, Sur y Altos de Jalisco (2004 y 2005). Las líneas promisorias también se sometieron a pruebas de calidad culinaria (2007) y a trabajos de caracterización varietal en 2008, con fines de registro. En los viveros, ensayos de rendimiento y parcelas de validación, como variedad testigo común se utilizó a la variedad 'Azufrado Tapatío', excelente cultivar comercial para el centro de Jalisco (Alemán y Núñez, 1999; Lépiz et al., 2007).

Como resultado del trabajo desarrollado, se identificaron y seleccionaron dos líneas de alto valor agronómico y grano comercial para Jalisco. La línea FM-98048 del tipo 'Flor de Mayo' (Figura 1) procedente del INIFAP, resultó similar en hábito de crecimiento, precocidad y rendimiento de grano a la variedad testigo 'Flor de Mayo M-38' (Cuadros 1 y 3), pero con mayor resistencia a antracnosis, grano más grande y de color menos oscuro. Con base en estas últimas tres características, en marzo de 2009 dicha línea se inscribió en el Catálogo Nacional de Variedades Vegetales (CNVV) del Servicio Nacional de Inspección y Certificación de Semillas (SNICS) con el nombre de 'Amapolo', con el registro FRI058-240209.

Por su parte, la línea NAB 69 de tipo 'Negro Jamapa' (Figura 2), proveniente del vivero internacional de progenitores donantes de genes (VIPADOGEN) del Centro Internacional de Agricultura Tropical (CIAT), resultó resistente a antracnosis y de hábito indeterminado erecto, y superior en rendimiento de grano a la variedad testigo 'Negro Cotaxtla' (Cuadro 2). Tanto en los viveros de evaluación como en las pruebas de validación, esta línea resultó superior a ambos testigos (Cuadro 3). Este tipo de frijol tiene demanda en Jalisco por las empresas empacadoras de granos. En marzo de 2009 se inscribió oficialmente en el CNVV del SNICS con el nombre de 'Mulato', con el registro FRI-055-240209. 
Ambas variedades, 'Amapolo' y 'Mulato', que también mostraron ser resistentes a bacteriosis de halo, son aptas para siembras de temporal o secano entre el 20 de julio y 10 de agosto, en suelos francos, franco-arenosos o ligeramente arcillosos, de buen drenaje, en las regiones Centro, Sur y Altos del Estado de Jalisco.

\section{BIBLIOGRAFÍA}

Alemán M V, S Núñez G (1999) Guía para producir frijol en Los altos y Centro de Jalisco. Agenda Técnica Núm. 2. Campo Experimental
Altos de Jalisco. CIRPAC, INIFAP. Tepatitlán, Jal. $36 \mathrm{p}$.

Lépiz I R, E López A, J L Martínez R, R. Rodríguez R, S de la Paz G, M Morales R (2001) Desarrollo de variedades de frijol para el Occidente de México. Scientia-CUCBA 3:86-93.

Lépiz I R, S Sánchez, E López, A González, S Núñez (2007) El cultivo de frijol en las regiones Centro y Sur de Jalisco. Tecnología para Altos Rendimientos. Universidad de Guadalajara. Las Agujas, Municipio de Zapopan, Jalisco, México. 34 p.

SIAP, Servicio de Información Agroalimentaria y Pesquera (2010) Anuario Estadístico de la Producción Agrícola. Cierre de la Producción Agrícola por Cultivo en Jalisco. Disponible en: http:/ www.siap.gob.mx. (Marzo 2011).

Cuadro 1. Rendimiento de grano $\left(\mathrm{kg} \mathrm{ha}^{-1}\right)$ de variedades de frijol, en seis ambientes del Estado de Jalisco, México.

\begin{tabular}{llllllll}
\hline \multirow{2}{*}{ Variedad } & TEPA & ZAPO & SAYU & ZAPO & Z A P O & SAYU & \multirow{2}{*}{ Media } \\
& 2002 & 2003 & 2003 & $07 / 2004$ & $08 / 2004$ & 2004 & \\
\hline 'Amapolo' & 2099 & 1736 & $1073 \mathrm{a}$ & $1731 \mathrm{a}$ & 1662 & 2733 & 1792 \\
'Azufrado Tapatío' & 1965 & 1880 & $893 \mathrm{ab}$ & $1447 \mathrm{ab}$ & 1924 & 3314 & 1951 \\
'Flor de Mayo M-38' & 1999 & 1905 & $748 \mathrm{~b}$ & $979 \mathrm{~b}$ & 1690 & 2934 & 1709 \\
\hline
\end{tabular}

Medias con letras iguales no son estadísticamente diferentes (DMS, 0.05). Localidades: TEPA $=$ Tepatitlán; ZAPO = Zapopan; SAYU = Sayula.

Cuadro 2. Indicadores de adaptación y rendimiento de grano $\left(\mathrm{kg} \mathrm{ha}^{-1}\right)$ de variedades de frijol en tres ambientes de Jalisco, en 2003 y 2004.

\begin{tabular}{lccccccc}
\hline Variedad & ADV & VAG & ANT & ZAPO & ZAPO & ZAPO & Media \\
& 2003 & 2003 & $04 / 08$ & 2003 & $07 / 2004$ & $08 / 2004$ & \\
\hline 'Mulato' & 2 & 3 & 2 & $2259 \mathrm{a}$ & $1858 \mathrm{a}$ & $2004 \mathrm{a}$ & $2040 \mathrm{a}$ \\
'Azufrado Tapatío' & 3 & 4 & 2 & $2070 \mathrm{ab}$ & $1447 \mathrm{ab}$ & $1928 \mathrm{a}$ & $1815 \mathrm{ab}$ \\
'Negro Cotaxtla' & 3 & 5 & 5 & $1724 \mathrm{~b}$ & $1015 \mathrm{~b}$ & $1176 \mathrm{~b}$ & $1305 \mathrm{~b}$ \\
\hline
\end{tabular}

Medias con letras iguales no son estadísticamente diferentes (DMS, 0.05). ADV = adaptación vegetativa; VAG $=$ valor agronómico; $\mathrm{ANT}=$ antracnosis; $\mathrm{ZAPO}=$ Zapopan. Escala de evaluación: 1,2 y 3 = bueno; 4,5 y 6 = intermedio; 7,8 y $9=$ deficiente.

Cuadro 3. Rendimiento de grano $\left(\mathrm{kg} \mathrm{ha}^{-1}\right)$ del ensayo de validación técnica de variedades de frijol en seis localidades del Centro, Sur y Altos de Jalisco, durante 2005.

\begin{tabular}{lccccccc}
\hline \multicolumn{1}{c}{ Variedad } & SAYU & ZAC & ZAPO & ACA & PON & TAP & Media \\
\hline 'Mulato' & 3089 & 1282 & 1816 & 2267 & 2858 & 2221 & $2256 \mathrm{a}$ \\
'Amapolo' & 2660 & 1202 & 2187 & 1860 & 2125 & 2148 & $2030 \mathrm{ab}$ \\
'Azufrado Tapatío' & 2883 & 1651 & 1974 & 1333 & 1718 & 2002 & $1922 \mathrm{~b}$ \\
\hline
\end{tabular}

SIG $=$ nivel de significancia; ${ }^{\star}$ diferencia significativa. Medias con letras iguales no son estadísticamente diferentes (DMS, 0.05). $\dagger$ Los rendimientos de las variedades por sitio, son promedio de dos repeticiones. Localidades: $\mathrm{SAY}=$ Sayula; $\mathrm{ZAC}=$ Zacoalco de Torres; $\mathrm{ZAPO}=$ Zapopan; ACA = Acatic; PON = Poncitlán; TAP = Tapias de Arriba.

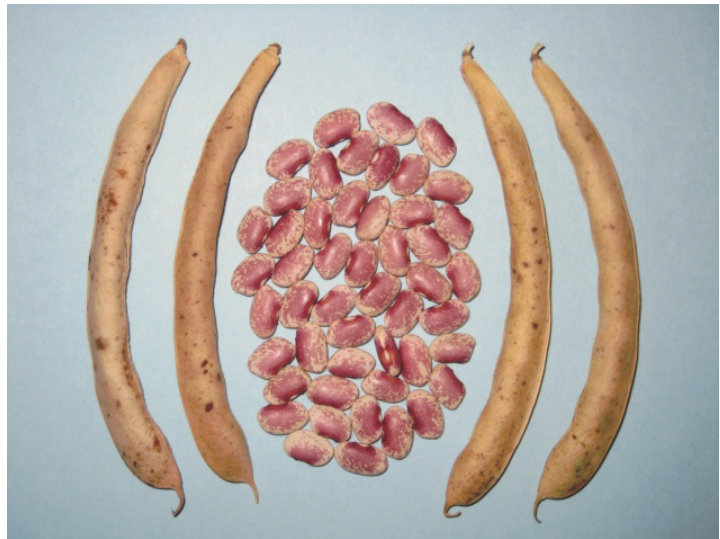

Figura 1. Frutos y semillas del frijol 'Amapolo'.

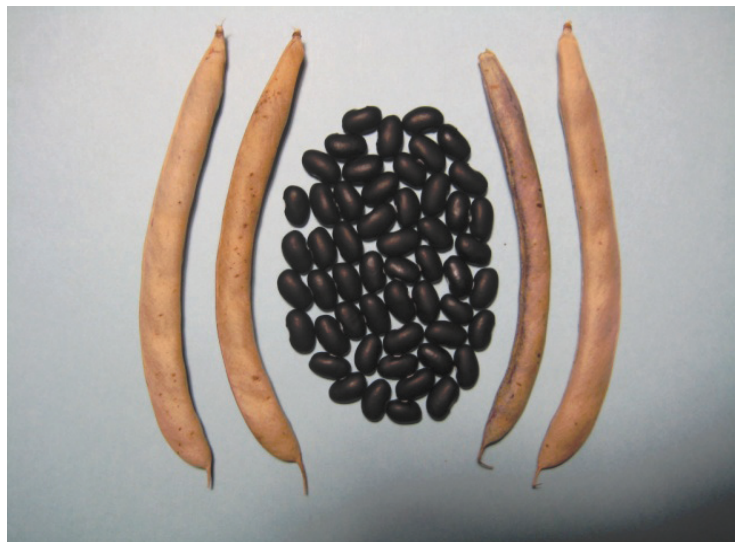

Figura 2. Frutos y semillas del frijol 'Mulato'. 